\title{
Alpacas in Poland: health, welfare, and anti-parasitic prophylaxis
}

\author{
(1) JOANNA KAPUSTKA ${ }^{1}$, (DALEKSANDRA GARBIEC ${ }^{2}$ \\ ${ }^{1}$ Department of Ethology and Wildlife Management, Faculty of Animal Ethology, \\ University of Life Science in Lublin, Akademicka 13, 20-950 Lublin, Poland \\ ${ }^{2}$ Department of Ethology and Wildlife Management, Faculty Animal Behavior and Welfare, \\ University of Life Science in Lublin, Akademicka 13, 20-950 Lublin, Poland
}

Kapustka J., Garbiec A.

Alpacas in Poland: health, welfare, and anti-parasitic prophylaxis

Summary

Alpacas' population in Poland has attained 5000 individuals. From 2020 alpacas are recognized as farm animals in Poland. This ruminant is increasingly popular, but still poorly known compared to other farm animals (cattle, sheep, goats). The aim of this review is to present the specificity of alpacas in terms of adequate welfare of these animals. To provide an appropriate welfare level, the knowledge about the species' biology and typical behaviour is needed. The basis for assessment of the animal's health status is the knowledge of basic physiological indicators, whose divergence from reference values is often the first symptom of many diseases. The health and welfare of virtually all animal species are influenced by infestations by endo- and exoparasites, which can cause many disorders and serious diseases. The growing alpaca population size necessitates investigation of this species, which will help future and current owners to breed these animals and prompt veterinarians to apply appropriate treatment of alpacas bred in Poland.

Keywords: alpaca, physiological parameters, behaviour, parasites

In December 2020 alpacas were recognized as farm animals in Poland after almost two-year long proceedings. This fact together with the previous establishment and functioning of alpaca breeders' associations: the Polish Alpaca Breeders Association founded in 2012 and the Alpaca and Llama Breeders Association confirms the increase in the popularity and number of alpacas kept in Poland. As reported by PZHA (online), there are approximately 70 alpaca breeders and owners registered in the associations in Poland. The alpaca population is estimated at approx. 5,500 individuals (Alpakotela Farm, 2020 - unpublished data). The growing alpaca population size necessitates investigation of this species, which will help future and current owners to breed these animals and prompt veterinarians to apply appropriate treatment of alpacas bred in Poland. The aim of this review is to present the specificity of alpacas in terms of adequate welfare of these animals.

\section{Taxonomy and domestication}

In terms of systematic classification, the alpaca represents ungulates: the family Camelidae and the genus Vicugna (26). The species was domesticated 6-7 thousand years ago on the Altiplano plateau in South America. The area occupies parts of Peru, Chile, and Bolivia $(32,39)$. Initially, the systematic classification of alpacas was unclear and there were several hypotheses on their ancestor species. The first hypothesis assumes that guanaco (Lama guanicoe) is the ancestor of the llama and the alpaca, whereas the fourth of species that are collectively called South American Camelids (SACs), i.e. vicuña (Vicugna vicugna), has never been domesticated. According to another hypothesis, the llama comes from the guanaco and the alpaca is a hybrid between the domesticated llama and the wild vicuña. The third hypothesis proposes that the llama and the alpaca are domesticated forms of guanaco and vicuña, respectively (39). Genetic studies have clearly supported the latter hypothesis; i.e. the alpaca comes from the vicuna, which contributed to the change of the Latin name and classification of the alpaca from the genus Lama (species name - Lama pacos) to the genus Vicugna (species name - Vicugna pacos) (21). All species of South American camelids have the same karyotype $(2 \mathrm{n}=74)$. They can interbreed and produce fertile offspring (9). 


\section{Biology}

Alpacas, similar to cattle, sheep, and goats (ruminants), ruminate food, but due to a different structure their stomach consists of three compartments (called Compartment 1,2,3), which are not analogous to the compartments in ruminant stomach, are not ruminants $(7,10)$. Sometimes they are named pseudoruminats. All compartments have glandular epithelium and no greater omentum. The spiral colon has five coils (9). As in the case of ruminants, alpacas have no upper incisors. Alpacas breathe through nostrils, and breathing through the mouth is not a natural process in these animals $(9,19)$. Another trait which distinguish alpacas from ruminants is the anatomical construction of distal parts of limbs. In alpacas, comparing to ruminants, foot pads occur (Suborder: Tylopoda "padded foot"), not cloven hoof $(10,26,32)$. Interesting features of blood count in camelids should be also noted. Red blood cells of this animals are elliptical and smaller than in ruminants (10), which makes them more resistant to changes in blood osmotic pressure and thus surviving states of severe dehydration (40). Despite of this, heat stress for alpacas is as dangerous as for other animals. Hyperthermia can lead to, for instance, organ damage, reproductive disorders and even death (11). Alpacas are sheared once a year, in Polish conditions it is in the spring-summer season (32). Abundant hair cover in summer months, when the temperature is high, limits the thermoregulatory abilities of animals. Shearing hair length to about $2 \mathrm{~cm}$ at an appropriate time is the best method of prevention heat stress in alpacas $(17,33)$. Additionally, alpacas have natural "thermal windows" (fibreless area): ventral abdomen, auxiliary space, inside of the thighs, therefore animals should have access to shaded places strewn with e.g. sand (where they can lie down). In hot weather, animals must have constant access to water. Hyperthermia signs can be: increased body temperature $\left(\sim 41^{\circ} \mathrm{C}\right.$ and higher $)$, mouth breathing, decreased or absence of rumination, reddening of the skin, increased heart rate, scrotal edema in males. If hyperthermia signs are observed, breeder's reaction must be immediate. The alpaca must be chilled e.g. by contact natural "thermal windows" with cold water (water should not be poured on the back and head), fluid administration (may be with addiction of physiological saline) and the provision of a shaded, well-oxygenated place (11).

In South American camelids, there is no typical rut with the estrus cycle. Ovulation is induced by copulation and occurs within 24 to 36 hours after mating, but the acceptance of the male by the female depends on the presence of maturing ovarian follicles with a diameter of at least $7 \mathrm{~mm}$. Typically, at least one such follicle is present in one or both ovaries $(9,37)$. A female that does not accept the male runs away spitting and kicking but lies still when the male is accepted (28). Copulation takes place in a recumbent position. Implantation occurs 20-22 days after copulation. Pregnancy lasts 335-350 days $(9,19)$, but some sources report a wider range of 316-367 days (37). The birth weight of neonates (called crias) is 6-10 kg; those with a body weight lower than $5.5 \mathrm{~kg}$ and body temperature below $36^{\circ} \mathrm{C}$ are considered low-birth weight neonates requiring special care (9). Delivery most often takes place in the morning, and the placenta should be expelled no later than within 4-6 hours after delivery, but it usually takes place earlier (19). The cria should stand up as soon as possible and drink the colostrum. Crias should be regularly weighed and their health status should be assessed. They may lose several hundred grams in the first 24 hours after birth, but they should double their birth weight within a month (9). The high mortality rate in crias is still a considerable problem (unpublished data). During the first days of life, the young suckle very often but in small amounts (only approximately $30 \mathrm{ml}$ of milk can be milked from a female at a time) (9).

The weight of adult animals is $55-90 \mathrm{~kg}$. There is no clear sexual dimorphism, but males are slightly larger and heavier (7). Regular body condition score (BCS) is important, as it is difficult to determine the animal's condition visually, especially in winter, due to the abundant hair coat. The measurement scale and the method for assessment of BCS have been described by Krajewska-Wędzina et al. (27).

\section{Health monitoring}

The inability of the organism to compensate fully for disease-related disorders is determined by the appearance of its first symptoms. Behavioral symptoms resulting from a disease are referred to as sickness behaviors $(4,16)$. These first symptoms are often easily noticeable to the owner. Sickness behaviors include loss of appetite and thirst, declining activity, inhibition of sexual behavior, weakening of maternal instinct, or impairment of cognitive functions (16). In alpacas, i.e. herbivorous animals, the dominance of active over passive behavior is observed. This is mainly associated with the fact that these herbivores consume low-energy food. During the day, alpacas staying on the pasture spend approximately $40 \%$ of the time feeding and ruminating and ca. $35 \%$ of time resting; the remaining time is spent on other activities related to active behavior (e.g. social behavior, grooming, movement) (23). As herd animals they are characterized by a very strong social instinct, and isolation of one individual from the herd is a strong stressor (34). Keeping these animals in separation worsens their welfare dramatically (22). Observable deviations from the norm in the activity of animals (isolation from the group, dominance of passive over active behavior, lower food consumption, no rumination or defecation) should arouse concern, as they may be the first symptoms of diseases.

In assessment of welfare, it is extremely important to know not only the time budget but also the ethogram of alpacas (i.e. behavior typical for the species). 
To provide the animal with behavioral comfort, the symptoms of stress, calmness, or interest should be known to be able to determine whether the animal feels safe in a given situation or would rather leave and avoid contact with an unpleasant stimulus. Pet Partners Organization (2016 - online data) has compiled a list of stress-related behaviors in alpacas:

- humming (especially lower frequency tones),

- screaming (high frequency, very loud, usually in conjunction with eyes wide open and head held high),

- tense facial muscles below eyes,

- visible red mucosa on the underside of the lower eyelid,

- ears pinned back,

- wide open eyes,

- drooling,

- rapid breathing, fast moving nostrils,

- tail clamped down tightly against the body or raised and pulled back,

- head raised and pulled back, ears laid back, nose pointing directly at the opponent - warning against a spit,

- leaning away from the human,

- stomping and kicking,

- spitting,

- walking away rapidly,

- agitation, inability to stand still.

Some of these behaviors such as raising the head (warning against spitting) or spitting are classified as defensive aggression (24). Humming conveys many meanings depending on the tone and intensity. Quiet and gentle humming may serve as an affiliative signal sent by animals grazing on the pasture (23). In turn, ears pointing forward or downwards in a relaxed manner, sniffing, standing quietly, calm observation, loosely kept tail, and relaxed body posture are signs of calmness and interest $(23,24$, Pet Partners Organization, 2016 - online data).

The next step involves application of a diagnostic procedure to determine the cause of disorders. One of the basic steps in medical and veterinary procedures is checking the basic parameters, i.e. the temperature, heart rate, and respiration rate. These parameters for alpacas are presented in Table 1.

The temperature is measured per rectum. The heart rate can be measured on the caudal artery, on the hairless part of the forelimb (groin area) (9), and in the inner area of the hind limb at the knee level (14). The respiration rate is best measured by auscultation (14) or by observation of respiratory movements (14, 19). The latter, however, may be disrupted by movements of the anterior compartment of the stomach, which contracts 3-5 times per minute (9). A problem with the correct determination of the basic parameters may be the fact that the abdomen, tail, and sometimes legs in many alpacas are not desensitized; therefore, touching these parts of the body during examination may be stressful to the animal and thus increase the values of examined indicators (own observations). The basic health assessment of alpacas also consists in evaluation of the color of the gums and sclera and the appearance of feces. The gums should be pink and moist. Gum pallor may indicate anemia or severe stress, whereas excessive redness suggests sepsis, heat stress, or dehydration, i.e. life-threatening conditions. The sclera in the alpaca is not readily visible; hence, the lower eyelid needs to be pulled down to check its color. It should be white with visible blood vessels but not bloodshot. An excessively pale sclera may be an indicator of a strong parasitic infestation, whereas an intensely red and bloodshot sclera is a symptom of infection or sepsis. Normal alpaca feces should be shaped as small pellets that do not stick together (as in sheep, goats, or wild ruminants) (19). Alpacas in the pasture and indoors establish so-called latrines, i.e. places where the entire herd defecates (31), although not all individuals always follow this rule and sometimes defecate outside the latrines (own observations). Alpacas do not graze around the latrine (31).

A better picture of an animal's health status can be provided by regular blood tests. The Tables show the normal ranges of blood morphological (Tab. 2) and

Tab. 1. Alpacas' physiological parameters: temperature, heart rate, respiratory rate $(12,15)$

\begin{tabular}{|l|c|c|}
\hline \multicolumn{1}{|c|}{ Parameter } & Mature animals & $\begin{array}{c}\text { Immature animals } \\
\text { (<6 month of life })\end{array}$ \\
\hline Temperature & $37.4-38.3^{\circ} \mathrm{C}$ & $37-38^{\circ} \mathrm{C}$ \\
Heart rate & $60-90 / \mathrm{min}$ & no data available \\
Respiratory rate & $10-30 / \mathrm{min}$ & no data available \\
\hline
\end{tabular}

Tab. 2. Morphological blood parameters in alpacas $(12,13)$

\begin{tabular}{|l|c|c|}
\hline \multicolumn{1}{|c|}{ Parameter } & Mature animals & $\begin{array}{c}\text { Immature animals } \\
\text { (<6 month of life) }\end{array}$ \\
\hline Erythrocytes & $10.5-17.2 \times 10^{12} / \mathrm{L}$ & $9.6-17.2 \times 10^{12} / \mathrm{L}$ \\
\hline Size erythrocytes $(\mu \mathrm{m})$ & $3.2-6.5$ & no data available \\
\hline RBCs lifespan in days & $60-225$ & no data available \\
\hline Hemoglobin (g/L) & $119.0-194.0$ & $101.0-181.0$ \\
\hline PCV (\%) & $27.0-45.0$ & $24.0-28.5$ \\
\hline MCV (fl/cell) & $22.2-29.9$ & $21.5-29.9$ \\
\hline MCH (pg/cell) & $10.1-12.7$ & $9.0-11.9$ \\
\hline MCHC (g/L) & $39.3-46.8$ & $39.4-44.9$ \\
\hline Leukocyte & $8.0-21.4 \times 10^{9} / \mathrm{L}$ & $7.1-22.9 \times 10^{9} / \mathrm{L}$ \\
\hline Granulocyte/agranulocyte & 1.54 & no data available \\
ratio & $41.7-72.9$ & $34.9-63.0$ \\
\hline Neutrophils (\%) & $9.2-25.2$ & $18.3-41.9$ \\
\hline Lymphocytes (\%) & $0.0-4.6$ & $0.0-5.2$ \\
\hline Monocytes (\%) & $2.2-21.4$ & $0.0-9.5$ \\
\hline Eosinophils (\%) & $0.0-14.0$ & $0.0-1.0$ \\
\hline Basophils (\%) & $200-600 \times 10^{3} / \mathrm{mm}^{3}$ & $268-913 \times 10^{3} / \mathrm{mm}^{3}$ \\
\hline Thrombocytes & $0.0-0.4$ & $0.0-7.5$ \\
\hline Reticulocytes (\% RBCs) & & \\
\hline
\end{tabular}


Tab. 3. Biochemistry blood parameters in alpacas (13)

\begin{tabular}{|l|c|c|}
\hline \multicolumn{1}{|c|}{ Parameter } & Mature animals & $\begin{array}{c}\text { Immature animals } \\
(<12 \text { month of life })\end{array}$ \\
\hline Total protein (g/L) & $40.0-78.0$ & $49.0-71.0$ \\
\hline Albumin (g/L) & $31.0-52.0$ & $34.0-45.0$ \\
\hline Fibrinogen (mg/dL) & $100-500$ & $100-400$ \\
\hline Urea nitrogen (mmol/L) & $3.21-12.14$ & $4.28-18.0$ \\
\hline Creatinine (mmol/L) & $123.8-282.9$ & $114.9-212.2$ \\
\hline Glucose (mmol/L) & $4.11-8.55$ & $5.99-8.66$ \\
Calcium (mmol/L) & no data available & $2.15-2.68$ \\
\hline Phosphorus (mmol/L) & $0.84-2.36$ & $1.65-3.29$ \\
\hline Sodium (mmol/L) & $148.0-158.0$ & $149.0-153.0$ \\
Chloride (mmol/L) & $102.0-120.0$ & $102.0-114.0$ \\
\hline Potassium (mmol/L) & $3.7-6.1$ & $4.4-7.0$ \\
\hline Magnesium (mmol/L) & $0.82-1.44$ & $0.82-0.95$ \\
\hline Iron (mmol/L) & $12.54-26.5$ & $12.54-26.5$ \\
\hline
\end{tabular}

biochemical (Tab. 3) parameters for adult alpacas and crias.

\section{Internal parasites infections and deworming}

As reported by Franz et al. (13), alpacas can be hosts for such endoparasites as or protozoa (Protozoa), flukes (Trematoda), tapeworms (Cestoda), nematodes (Nematoda). Similar to other species of South American camelids, alpacas are usually infected by parasites which infect ruminants as well: sheep, goats, and cattle $(7,13)$. The so-called gastrointestinal infections by parasitic nematodes are diagnosed most frequently. The symptoms of severe parasitic invasion may be nonspecific (emaciation, weakness, and anemia), while diarrhea occurs mainly in crias and juveniles (13). Alpacas can occasionally be infected by flukes Fasciola magna, Fasciola hepatica, and Dicrocoelium dendtriticum (25). Dicroceliasis is particularly dangerous for SACs, as it causes severe pathological changes in the liver tissue and bile ducts, sometimes leading to death (25). Tapeworm infections in alpacas are not common. Nevertheless, cases of Taenia spp. (intermediate host) and Moniezia spp. (definitive host) infections have been reported, and monieziosis causing severe diarrhea may be more dangerous (9). Such protozoa species as Eimeria spp., Cryptosporidium spp., and Giardia spp. can be infected with SACs. The most common infections are caused by Eimeria spp. (e.g. Eimeria macusaniensis and Eimeria punoensis) $(13,20)$. Coccidia can cause diarrhea as well as colic, weight loss and even death in severe cases $(13,20,38)$.

The herd should not be dewormed prophylactically, but feces should be regularly examined and antiparasitic agents should be administered only when the number of parasite eggs in the stool indicates such a need (9). However, in the case of some species, e.g. Dicrocoelium dendriticum, Nematodirus battus, Teladorsagia spp., and Ostertagia spp., there is a weak correlation between the number of eggs in feces and the severity of invasion, which considerably hinders appropriate diagnosis (13). Stool analyses should be performed twice a year (preferably before and after the grazing season) and when disease symptoms occur. It is recommended that anthelmintic agents should be administered when the number of eggs per $1 \mathrm{~g}$ of feces exceeds 100 in under 1-year-old juveniles and 300 in adult animals (2). Albendazole may be toxic to the fetus and should not be used in pregnant female alpacas (2). The following drugs are used to fight parasitic infections: paromomycin and aminoglycoside against Cryptosporidium spp. (38) in dose of 25-100 $\mathrm{mg} / \mathrm{kg}$ BW orally twice daily (13), and sulfonamide antibiotics against Eimeria spp. in a dose of $15-30 \mathrm{mg} /$ $\mathrm{kg}$ BW orally once a day (20). Fenbendazole in a dose of $10-50 \mathrm{mg} / \mathrm{kg}$ BW orally, once a day against Giardia spp. (13). Triclabendazole in a single dose of $15 \mathrm{mg} /$ $\mathrm{kg} \mathrm{BW}$ orally is the most effective in the case of flukes (Fasciola hepatica, Faciola magna, D. dendriticum) (13). Praziquantel in a dose of $2.5-10 \mathrm{mg} / \mathrm{kg} \mathrm{BW}$ in the case of cestodes (12). Fenbendazole is also safe and an effective for the treatment Nematodirus, Strongyloides, and Trichuris in a dose of $5-20 \mathrm{mg} / \mathrm{kg}$ BW orally once a day $(3,5)$.

\section{External parasites infestations and parasitic diseases}

External parasitic infestations are a frequent problem not only to animals but also to their owners. A common health problem in the alpaca population is posed by scabies, i.e. infestations by Sarcoptes scabiei, Chorioptes spp., and Psoroptes spp. (9). Sarcoptes species mainly attack the head (including the mouth, ears, and the upper surface of the nose), inner thighs, skin between the toes, groin, perineum, and foreskin. In turn, Chorioptes species typically colonize the abdomen, inner thighs, nose, ears, and feet, whereas Psoroptes species attack the head (including ears) (6, 15). Mites are most easily spread through direct contact (15). Less hair covered body regions are the most sensitive areas (9). S. scabiei ver auchenia infestation of humans from alpacas has been reported as well. Scabies infestations are a nuisance, as some species burrow into the epidermis causing severe itching. Formation of scabs and hair loss are observed in infested areas. In addition to scabies, alpacas can be attacked by lice (Phthiriasis). Lice infestations are manifested by itching, restlessness, hair loss, and growth inhibition. Severe infestations may lead to anemia. Treatment of scabies and lice infestations consists in subcutaneous administration of ivermectin. As shown by Duncanson (9), fipronil may also be used in treatment of alpacas (e.g. in scabies infestations). This substance is also contained in anti-flea and anti-tick drops for dogs and cats, which is spread over the skin in secreted sebum. There is no indication, however, whether it can be used in this way to treat alpacas and whether it is effective. 
Despite the great interest expressed by alpaca owners, there is little information about the risk of infection of alpacas with tick-borne diseases. As reported by Bornstein (6), alpacas are attacked by ticks from the family Argasida and Ixodidae. The author (6) emphasizes that hard ticks (Ixodidae), which comprise most of the common tick species (Ixodes spp., Dermacentor spp.) attacking various species of mammals, can transmit many potentially dangerous pathogens. Tinkler et al. (36) describes a case of an alpaca infected by Anaplasma phagocytophilum, i.e. an intracellular parasite causing tick-borne fever transmitted by ticks of the genus Ixodes (primarily the castor bean tick I. ricinus in Europe). The symptoms of infection in this case included premature birth, high fever $\left(>40^{\circ} \mathrm{C}\right)$, abdominal distension, and ascites. The animal did not take food and did not defecate. The alpaca recovered after treatment. As suggested by Duncanson (9), the infection can also be accompanied by apathy, weight loss, and sometimes neurological symptoms. Nevertheless, researchers stress that cases of Anaplasma phagocytophilum infection are rare in camelids (36). Studies on camel populations in Saudi Arabia confirmed infections of these animals with such tick-borne pathogens as Hepatozoon canis, Ehrlichia canis, and Anaplasma sp., although H. canis and E. canis infections are regarded as non-specific to camels. The study did not demonstrate infection with Babesia spp. and Theileria spp. (1), but these pathogens were detected in camels by Lorusso et al. (29). Although ticks species attacking camels do not occur in the study area in northern Europe, the native species of ticks (mainly the castor bean tick) may also be vectors of these pathogens. As demonstrated by Duncanson (9), alpacas can develop babesiosis. B. motasi and B. capreoli infections have been reported in alpacas in the UK, but the prevalence of the disease is low in SACs. No pathogenic activity of Theileria spp. has been identified so far in this species (9). There is very little research on Borelia spp. infections in alpacas. Examinations of zoo animals in Germany have confirmed the presence of $B$. burgdorferis infection in one of the 22 tested alpacas; unfortunately, it was not known whether the bacteria led to the development of Lyme disease in this individual (35). The presence of ticks in the ear canal may be one of the etiological factors of otitis media (9). A less known tick-borne disease is louping ill in sheep caused by the encephalitis virus. Its presence has also been confirmed in llamas and alpacas. The castor bean tick is its vector. The disease occurs mainly in the British Isles (18). The most common neurological symptom is the leaping behavior (18). Other symptoms include miscarriages or birth of crias with neurological symptoms (9). In addition to the transmission of various pathogens, ticks can be dangerous to health by production of toxins that enter the host's bloodstream with tick saliva $(1,9)$. Severe infestations can cause anemia and debilitation of the animal as well as skin damage (1). Since alpaca fiber does not contain lanolin, the application of pour-on formulations to prevent infestation with ectoparasites is ineffective (9). As reported by Duncanson (9), a solution to this problem may be offered by protection of surfaces with insecticides containing alpha-cypermethrin, cypermethrin, or deltamethrin. Crucially, these are highly poisonous agents and should not be used in places where animal feed is present; therefore, their use in pastures is limited. The products are usually sprayed on walls, pavements, and floors, but they should be used with special caution. They have a killing effect on flying and running insects, and therefore on ticks.

\section{Conclusion}

Although they are increasingly popular, alpacas are still poorly known. Fortunately, this is changing and there are greater numbers of reliable sources of knowledge of the health, breeding, and behavior of this species: $7,8,9,11,12,27,30$. All this information is necessary to provide the animals with optimal housing conditions that will fully meet their needs and thus ensure a high level of welfare. The basis for assessment of the animal's health status is the knowledge of basic physiological indicators, whose divergence from reference values is often the first symptom of many diseases. The health and welfare of virtually all animal species are influenced by infestations by endoand exoparasites, which can cause many disorders and serious diseases. Therefore, regular monitoring of the health status in the herd to detect their presence and symptoms of other diseases is extremely important.

\section{References}

1. Alanazi A. D., Nguyen V. L., Alyousif M. S., Manoj R. R. S., Alouffi A. S. et al.: Ticks and associated pathogens in camels (Camelus dromedarius) from Riyadh Province, Saudi Arabia. Parasite Vector 2020, 13, 1-9, doi: 10.1186/ s13071-020-3973-y.

2. Australian Alpaca Association. Husbandry worms and alpacas. Animal Health, Husbandry \& Welfare Committee 2008, 11, 1-2.

3. Ballweber L. R.: Endoparasite Control, [in:] Cebra C., Anderson D., Tibary A., Van Saun R., Johnson Laure W.: Llama and Alpaka Care. Medicine, Surgery, Reproduction, Nutrition and Herd Health 2014, 1, 12-16.

4. Barszcz K., Kupczyńska M., Kobryń H.: Impact of chosen biological pathogens on some nervous system structures and on animal behaviour. Kosmos. Problemy Nauk Biologicznych 2010, 59, 71-81.

5. Beier E., Lehenbauer T. W., Sangiah S.: Clinical efficacy of fenbendazole against gastrointestinal parasites in llamas. Small Ruminant Research 2000, $36,17-23$.

6. Bornstein S.: Important ectoparasites of Alpaca (Vicugna pacos). Acta Vet. Scand. 2010, 52, 27, doi: 10.1186/1751-0147-52-s1-s17.

7. Bravo P. W.: Camelidae. In Fowler's Zoo and Wild Animal Medicine 2015, 8, 592-602.

8. Cebra C., Anderson D., Tibary A., Van Saun R., Johnson Laure W.: Llama and Alpaka Care, Elseveier, USA 2013, doi: 10.1016/B978-1-4377-2352-6.00066-3.

9. Duncanson G. R.: Veterinary Treatment of Llamas and Alpacas. Westover Veterinary Centre, UK 2012.

10. Fowler M. E.: Camelids Are Not Ruminants, Zoo and Wild Animal Medicine 2008, 375-385

11. Fowler M. E.: Hyperthermia in llamas and alpacas. Vet. Clin. North. Am. Food. Anim. Pract. 1994, 10, 309-317.

12. Fowler M. E.: Medicine and Surgery of Camelids. Wiley-Blackwell. $3^{\text {ed }}$, USA 2010.

13. Franz S., Wittek T., Joachim A., Hinney B., Dadak A. M.: Llamas and alpacas in Europe: Endoparasites of the digestive tract and their pharmacotherapeutic control. Vet. J. 2015, 204, 255-262, doi: 10.1016/j.tvj1.2015.04.019. 
14. Garner-Paulin E.: Alpaca Emergency Care and First Aid. Animal Health and Welfare Article 2006, 50, 8-10.

15. Geurden T., Deprez P., Vercruysse J.: Treatment of sarcoptic, psoroptic and chorioptic mange in a Belgian alpaca herd. Vet. Rec. 2003, 153, 331-332, doi: 10.1136/vr.153.11.331

16. Gliński Z., Kostro K.: Odporność behawioralna. Życie Wet. 2018, 93, 86-89.

17. Heath A. M., Navarre C. B., Simpkins A., Purohit R. C., Pugh D. G.: A comparison of surface and rectal temperatures between sheared and non-sheared alpacas (Lama pacos). Small Rumin. Res. 2001, 39, 19-23.

18. Jeffries C. L., Mansfield K. L., Phipps L. P., Wakeley P. R., Mearns R et al.: Louping ill virus: An endemic tick-borne disease of Great Britain. J. Gen. Virol. 2014, 95, 1005-1014, doi: 10.1099/vir.0.062356-0.

19. Jenkins H. B.: Alpaca general medicine lecture. Galax, VA 2012.

20. Johnson A. L., Stewart J. E., Perkins G. A.: Diagnosis and treatment of Eimeria macusaniensis in an adult alpaca with signs of colic. Vet. J. 2009, 179, 465-467, doi: 10.1016/j.tvj1.2007.10.012.

21. Kadwell M., Fernandez M., Stanley H. F., Baldi R., Wheeler J. Cet al.: Genetic analysis reveals the wild ancestors of the llama and the alpaca. Proceedings of the Royal Society B. Biological Sciences 2001, 268 (1485), 2575-2584, doi: 10.1098/rspb.2001.1774

22. Kapustka J.: Podstawowe aspekty dobrostanu alpak w Polsce. XII Interdyscyplinarna Konferencja Naukowa Tygiel, online, 2020, p. 107.

23. Kapustka J., Budzyńska M.: Behaviour traits of alpacas based on pasture and stable observations (Cechy behawioru alpak na podstawie obserwacji na pastwisku i w alpakarni) (in Polish). Wiad. Zootech. 2018, 128-136.

24. Kapustka J., Budzyńska M.: Human ability to interpret alpaca body language. J. Vet. Behav. 2021, 42, 16-21, doi: 10.1016/j.jveb.2020.12.003.

25. Klein D., Prosl H., Thaller D.: Diagnosis of a Dicrocoelium dendriticum infection in New World Camelids: a case report. Vet. Med-Czech. 2012, 57, 154-162.

26. Komosińska H., Podsiadło E.: Ssaki kopytne. Przewodnik PWN, Polska 2002

27. Krajewska-Wędzina M., Najbar J., Turcewicz P., Raczyńska A.: Alpaki-nowy gatunek hodowlany w Polsce. Część II. Hodowla i żywienie. Życie Wet. 2020, 95, 756-761.

28. Lichtenwalner A. B., Woods G. L., Weber J. A.: Male llama choice between receptive and nonreceptive females. Appl. Anim. Behav. Sci. 1998, 59, 349-356, doi: 10.1016/S0168-1591(98)00143-9.
29. Lorusso V., Wijnveld M., Latrofa M. S., Fajinmi A., Majekodunmi A. O. et $a l .:$ Canine and ovine tick-borne pathogens in camels, Nigeria. Vet. Parasitol. 2016, 228, 90-92, doi: 10.1016/j.vetpar.2016.08.014.

30. McGee Bennett M.: The Camelid Companion: Handling and Training Your Alpacas and Llamas. Raccoon Press, USA 2001.

31. McGregor B. A.: Comparative productivity and grazing behaviour of Huacaya alpacas and Peppin Merino sheep grazed on annual pastures. Small Ruminant Res. 2002, 44, 219-232, doi: 10.1016/S0921-4488(02)00050-0.

32. Morales Villavicencio A.: Chów alpak. Multico Oficyna Wydawnicza, 1. ed., Polska 2010.

33. Navarre C. B., Heath A. M., Wenzel J., Simpkins A., Blair E., Belknap E., Pugh $D$. $G$.: A comparison of physical examination and clinicopathologic parameters between sheared and nonsheared alpacas (Lama pacos). Small Rumin. Res. 2001, 39, 11-17.

34. Pollard J., Littlejohn R.: Effects of social isolation and restraint and behaviour of alpacas on heart rate. Appl. Anim. Behav. Sci. 1995, 45, 165-174.

35. Stoebel K., Schoenberg A., Streich W. J.: The seroepidemiology of Lyme borreliosis in zoo animals in Germany. Epidemiol. Infect. 2003, 131, 975-983, doi: $10.1017 / \mathrm{S} 0950268803008896$.

36. Tinkler S. H., Firshman A. M., Sharkey L. C.: Premature parturition, edema, and ascites in an alpaca infected with Anaplasma phagocytophilum. Canadian Vet. J. 2012, 53, 1199-1202.

37. Vaughan J. L., Macmillan K. L., Anderson G. A., D'occhio M. J.: Effects of mating behaviour and the ovarian follicular state of female alpacas on conception. Aust. Vet. J. 2003, 81, 86-90.

38. Waitt L. H., Cebra C. K., Firshman A. M., McKenzie E. C., Schlipf J. W. Cryptosporidiosis in 20 alpaca crias. J. Am. Vet. Med. Assoc. 2008, 233, 294-298, doi: 10.2460/javma.233.2.294.

39. Wheeler J. C.: Evolution and present situation of the South American camelidae. Biol. J. Linn. Soc. 1995, 54, 271-295, doi: 10.1016/0024-4066(95)90021-7. 40. Yagil R., Sod-Moriah U. A., Meyerstein N.: Dehydration and camel blood. II. Shape, size and concentration of red blood cells. Am. J. Physiol. 1974, 226 (2), 301-304.

Corresponding author: Aleksandra Garbiec, DVM, ul. Akademicka 13, 20-950 Lublin, Poland; e-mail: aleksandra.garbiec@up.lublin.pl 